\title{
BILANGAN KROMATIK LOKASI GRAF TAK TERHUBUNG DENGAN GRAF LINTASAN DAN GRAF LINGKARAN SEBAGAI KOMPONEN-KOMPONENNYA
}

\author{
SUCI RAHMA PUTRI, DES WELYYANTI, NARWEN \\ Program Studi S1 Matematika, \\ Fakultas Matematika dan Ilmu Pengetahuan Alam, Universitas Andalas, \\ Kampus UNAND Limau Manis Padang, Indonesia, \\ email : sucirahmaputrii@gmail.com
}

\begin{abstract}
Abstrak. Misalkan $S_{i}$, merupakan himpunan titik-titik yang berwarna $i$ dengan $1 \leq i \leq$ $k$ maka $\Pi=\left\{S_{1}, S_{2}, \cdots, S_{k}\right\}$ adalah himpunan yang terdiri dari kelas-kelas warna di $V(G)$. Berdasarkan suatu pewarnaan titik, maka representasi $v$ terhadap $\Pi$ disebut kode warna dari $v$, dinotasikan dengan $c_{\Pi}(v)$. Kode warna $c_{\Pi}(v)$ dari suatu titik $v \in V(G)$ didefinisikan sebagai $k$-vektor,

$$
c_{\Pi}(v)=\left(d\left(v, S_{1}\right), d\left(v, S_{2}\right), \cdots, d\left(v, S_{k}\right)\right)
$$

dimana $d\left(v, S_{i}\right)=\min \left\{d(v, x) \mid x \in S_{i}\right\}$ untuk $1 \leq i \leq k$. Jika setiap titik yang berbeda di $G$ memiliki kode warna yang berbeda untuk suatu $\Pi$, maka $c$ disebut pewarnaan lokasi dari $G$. Bilangan bulat positif terkecil $k$ sedemikian sehingga $G$ mempunyai $k$ pewarnaan lokasi dinamakan bilangan kromatik lokasi dari $G$, dan dinotasikan dengan $\chi_{L}(G)$. Penelitian ini akan memperluas mengenai bilangan kromatik lokasi dapat diaplikasikan pada semua jenis graf termasuk graf tak terhubung. Khususnya akan ditentukan bilangan kromatik lokasi graf tak terhubung dengan graf lintasan $\left(P_{n}\right)$ dan graf lingkaran $\left(C_{m}\right)$ sebagai komponen-komponennya dimana graf lintasan dengan $n$ titik dan graf lingkaran dengan $m$ titik.
\end{abstract}

Kata Kunci: Kelas warna, Kode warna, Pewarnaan lokasi, Bilangan kromatik lokasi, Graf tak terhubung, Graf lingkaran, Graf lintasan

$\begin{array}{lll}\text { Diterima } & : & \text { 26 Juli } 2018 \\ \text { Direvisi } & : & \text { 17 September 2018 } \\ \text { Dipublikasikan } & : & \text { 21 Desember 2018 }\end{array}$

\section{Pendahuluan}

Kajian tentang konsep pewarnaan lokasi graf pertama kali dikaji oleh Chartrand dkk, dengan menentukan suatu bilangan kromatik lokasi dari beberapa graf seperti, graf lintasan $P_{n}$ dengan $n \geq 3$ diperoleh bilangan kromatik lokasi, $\chi_{L}\left(P_{n}\right)=3$. Untuk graf lingkaran diperoleh $\chi_{L}\left(C_{n}\right)=3$ untuk $n$ ganjil atau $\chi_{L}\left(C_{n}\right)=4$ untuk $n$ genap.

Selanjutnya, Asmiati dkk [1] membahas mengenai konsep pewarnaan lokasi graf seperti menentukan bilangan kromatik lokasi pada graf kembang api dan mengkarakterisasi semua graf yang memuat siklus berbilangan kromatik lokasi tiga. Lebih lanjut masalah penentuan bilangan kromatik lokasi terus dibahas hingga 
muncul perluasan dari kajian ini dimana pengertian bilangan kromatik lokasi dapat diaplikasikan pada semua jenis graf termasuk graf tak terhubung. Pada tulisan ini akan dibahas tentang bilangan kromatik lokasi untuk salah satu kelas graf tak terhubung dengan graf lintasan dan graf lingkaran sebagai komponennya.

\section{Tinjauan Teori}

Misalkan $H$ adalah graf tak terhubung dan $c$ adalah suatu pewarnaan titik pada graf $G$ dengan menggunakan warna $1,2, \cdots, k$ untuk suatu bilangan bulat positif $k$. I merupakan suatu partisi terurut dari $V(G)$ kedalam kelas-kelas warna yang saling lepas $C_{1}, C_{2}, \cdots, C_{k}$ yang mana titik-titik di $C_{i}$ berwarna $i, 1 \leq i \leq k$. Pewarnaan $c$ dikatakan pewarnaan lokasi- $k$ jika semua kode warna dari semua titik di $H$ berbeda. Bilangan kromatik lokasi dari graf tak terhubung $H, \chi_{L}^{\prime}(H)$, adalah bilangan bulat positif terkecil $k$ sedemikian sehingga $H$ mempunyai $k$-pewarnaan lokasi. Jika tidak ada nilai $k$ yang memenuhi maka $\chi_{L}^{\prime}(H)=\infty$. Sehingga bilangan kromatik lokasi untuk graf tak terhubung dapat bernilai hingga dan tak hingga.

Teorema 2.1. [5] Untuk setiap $i$, misal $G_{i}$ adalah suatu graf terhubung dan misalkan $H \simeq \bigcup_{i=1}^{m} G_{i}$. Jika $\chi_{L}^{\prime}(H)<\infty$, maka $q \leq \chi_{L}(H) \leq r$, dimana $q=\max \left\{\chi_{L}\left(G_{i}\right): i \in[1, m]\right\}$ dan $r=\min \left\{\left|V\left(G_{i}\right)\right| i \in[1, m]\right\}$.

Teorema 2.2. [5] Misalkan $H=\bigcup_{i=1}^{t} P_{n_{i}}, r=\min \left\{n_{i} \mid i \in[1, t]\right\}$, jika $\chi_{L}^{\prime}(H)<\infty$, maka $3 \leq \chi_{L}^{\prime}(H) \leq r$. Secara khusus, $\chi_{L}^{\prime}(H)=3$ disebabkan oleh $t=1,2$ atau 3.

\section{Bilangan Kromatik Lokasi Graf Tak Terhubung $H=P_{n} \cup C_{m}$}

Graf $H$ merupakan graf tak terhubung yang memuat graf lintasan $P_{n}$ dengan $n$ titik dan graf lingkaran $C_{m}$ dengan $m$ titik sebagai komponen-komponennya yang dinotasikan sebagai $H=P_{n} \cup C_{m}$.

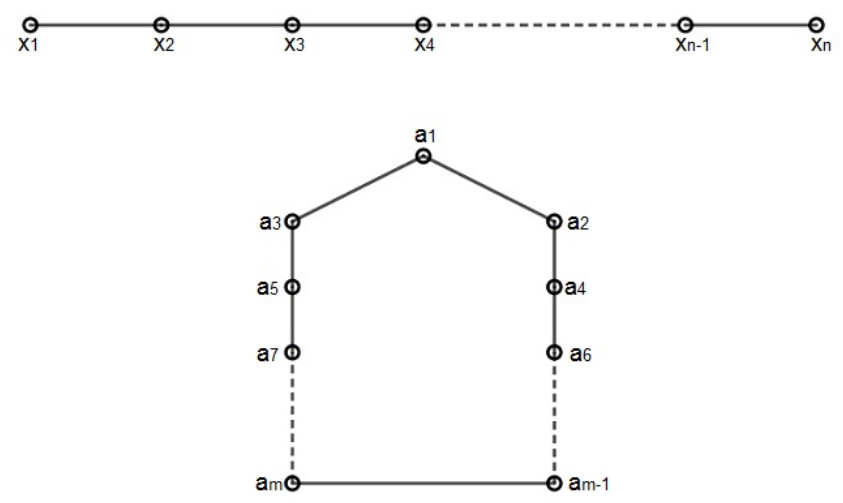

Gambar 1. Graf $H=P_{n} \bigcup C_{m}$ 
Misalkan himpunan sisi dan himpunan titik dari graf tak terhubung $H$ sebagai berikut.

$$
\begin{aligned}
V(H)= & V\left(P_{n}\right) \bigcup V\left(C_{m}\right) \\
= & \left\{x_{1}, x_{2}, \cdots, x_{n}\right\} \bigcup\left\{a_{1}, a_{2}, \cdots, a_{m}\right\} \\
E(H)= & E\left(P_{n}\right) \bigcup E\left(C_{m}\right) \\
= & \left\{x_{1} x_{2}, x_{2}, x_{3}, \cdots, x_{n-1} x_{n}\right\} \\
& \bigcup\left\{a_{1} a_{2}, a_{1} a_{3}, a_{2}, a_{4}, a_{3} a_{5}, a_{4} a_{6}, a_{5} a_{7}, \cdots, a_{m-1} a_{m}\right\}
\end{aligned}
$$

Teorema 3.1. Misalkan $H=P_{n} \bigcup C_{m}$. Maka $\chi_{L}^{\prime}(H)=\infty$ untuk $n=2$ dan $m \geq 3$.

Bukti. Pembuktian ini akan dibagi kedalam dua kasus sebagai berikut.

Kasus 1. Untuk $n=2$, dan $m=3$.

Misalkan $c$ adalah pewarnaan titik untuk graf $H$, yakni $c: V(H) \rightarrow\{1,2,3\}$ sedemikian sehingga

$$
\begin{aligned}
& c\left(x_{1}\right)=c\left(a_{1}\right)=1, \\
& c\left(x_{2}\right)=c\left(a_{2}\right)=2, \\
& c\left(a_{3}\right)=3 .
\end{aligned}
$$

Dari pemisalan pewarnaan titik diatas terlihat bahwa setiap titik bertetangga diwarnai dengan warna yang berbeda. Selanjutnya akan dilihat kode warna setiap titik di $H$ terhadap $\Pi$ juga berbeda. Misalkan kelas warna sebagai berikut $\Pi=\left\{S_{1}, S_{2}, S_{3}\right\}$ dengan

$$
S_{1}=\left\{x_{1}, a_{1}\right\}, S_{2}=\left\{x_{1}, a_{2}\right\}, S_{3}=\left\{a_{3}\right\} .
$$

Maka diperoleh kode warna pada setiap titik di $H$ terhadap $\Pi$ sebagai berikut,

$$
\begin{aligned}
& c_{\Pi}\left(a_{1}\right)=\left(d\left(a_{1}, S_{1}\right), d\left(a_{1}, S_{2}\right), d\left(a_{1}, S_{3}\right)\right), \\
& =(0,1,1) \text {, } \\
& c_{\Pi}\left(a_{2}\right)=\left(d\left(a_{2}, S_{1}\right), d\left(a_{2}, S_{2}\right), d\left(a_{2}, S_{3}\right)\right), \\
& =(1,0,1) \text {, } \\
& c_{\Pi}\left(a_{3}\right)=\left(d\left(a_{3}, S_{1}\right), d\left(a_{3}, S_{2}\right), d\left(a_{3}, S_{3}\right)\right), \\
& =(1,1,0) \text {, }
\end{aligned}
$$

Pada graf lintasan terdapat minimal satu titik di $S_{1}$ misal $x_{1}$ yang mempunyai $d\left(x_{1}, S_{3}\right)=\infty$. Sehingga dihasilkan kode warna sebagai berikut,

$$
\begin{aligned}
c_{\Pi}\left(x_{1}\right) & =\left(d\left(x_{1}, S_{1}\right), d\left(x_{1}, S_{2}\right), d\left(x_{1}, S_{3}\right)\right), \\
& =\left(d\left(x_{1}, x_{1}\right), d\left(x_{1}, x_{2}\right), d\left(x_{1}, a_{3}\right)\right), \\
& =(0,1, \infty) .
\end{aligned}
$$

Akibat dari kode warna diatas diperoleh $\chi_{L}^{\prime}(H)=\infty$. 
Kasus 2. Untuk $n=2$, dan $m \geq 4$.

Misalkan $c$ adalah pewarnaan titik di $H$ yakni $c: V(H) \longrightarrow\{1,2,3,4\}$ sedemikian sehingga

$$
\begin{aligned}
& c\left(x_{1}\right)=c\left(a_{1}\right)=1, \\
& c\left(x_{2}\right)=c\left(a_{4}\right)=2, \\
& c\left(a_{2}\right)=c\left(a_{5}\right)=c\left(a_{6}\right)=c\left(a_{m}\right)=3, \\
& c\left(a_{3}\right)=c\left(a_{7}\right)=c\left(a_{m-1}\right)=4 .
\end{aligned}
$$

Dari pemisalan pewarnaan titik diatas terlihat bahwa setiap titik bertetangga diwarnai dengan warna yang berbeda. Selanjutnya, akan dilihat kode warna setiap titik di $H$ terhadap $\Pi$ juga berbeda. Misalkan kelas warna sebagai berikut $\Pi=\left\{S_{1}, S_{2}, S_{3}, S_{4}\right\}$ dengan

$$
\begin{aligned}
& S_{1}=\left\{x_{1}, a_{1}\right\}, \\
& S_{2}=\left\{x_{2}, a_{4}\right\}, \\
& S_{3}=\left\{a_{2}, a_{5}, a_{6}, a_{m}\right\}, \\
& S_{4}=\left\{a_{3}, a_{7}, a_{m-1}\right\} .
\end{aligned}
$$

Maka diperoleh kode warna pada setiap titik di $H$ terhadap $\Pi$ sebagai berikut,

$$
\begin{aligned}
& c_{\Pi}\left(a_{1}\right)=\left(d\left(a_{1}, S_{1}\right), d\left(a_{1}, S_{2}\right), d\left(a_{1}, S_{3}\right), d\left(a_{1}, S_{4}\right)\right), \\
& =(0,2,1,1) \text {, } \\
& c_{\Pi}\left(a_{2}\right)=\left(d\left(a_{2}, S_{1}\right), d\left(a_{2}, S_{2}\right), d\left(a_{2}, S_{3}\right), d\left(a_{2}, S_{4}\right)\right) \text {, } \\
& =(1,1,0,2) \text {, } \\
& c_{\Pi}\left(a_{3}\right)=\left(d\left(a_{3}, S_{1}\right), d\left(a_{3}, S_{2}\right), d\left(a_{3}, S_{3}\right), d\left(a_{3}, S_{4}\right)\right) \text {, } \\
& =(1,3,1,0) \text {, } \\
& c_{\Pi}\left(a_{4}\right)=\left(d\left(a_{4}, S_{1}\right), d\left(a_{4}, S_{2}\right), d\left(a_{4}, S_{3}\right), d\left(a_{4}, S_{4}\right)\right) \text {, } \\
& =\left(2,0,1, d\left(a_{4}, S_{4}\right)\right), \\
& c_{\Pi}\left(a_{5}\right)=\left(d\left(a_{5}, S_{1}\right), d\left(a_{5}, S_{2}\right), d\left(a_{5}, S_{3}\right), d\left(a_{5}, S_{4}\right)\right) \text {, } \\
& =(2,4,0,1) \text {, } \\
& c_{\Pi}\left(a_{6}\right)=\left(d\left(a_{6}, S_{1}\right), d\left(a_{6}, S_{2}\right), d\left(a_{6}, S_{3}\right), d\left(a_{6}, S_{4}\right)\right) \text {, } \\
& =\left(3,1,0, d\left(a_{6}, S_{4}\right)\right), \\
& c_{\Pi}\left(a_{7}\right)=\left(d\left(a_{7}, S_{1}\right), d\left(a_{7}, S_{2}\right), d\left(a_{7}, S_{3}\right), d\left(a_{7}, S_{4}\right)\right), \\
& =\left(3, d\left(a_{7}, S_{2}\right), d\left(a_{7}, S_{3}\right), 0\right), \\
& c_{\Pi}\left(a_{m-1}\right)=\left(d\left(a_{m-1}, S_{1}\right), d\left(a_{m-1}, S_{2}\right), d\left(a_{m-1}, S_{3}\right), d\left(a_{m-1}, S_{4}\right)\right) \text {, } \\
& =\left(d\left(a_{m-1}, S_{1}\right), d\left(a_{m-1}, S_{2}\right), 1,0\right), \\
& c_{\Pi}\left(a_{m}\right)=\left(d\left(a_{m}, S_{1}\right), d\left(a_{m}, S_{2}\right), d\left(a_{m}, S_{3}\right), d\left(a_{m}, S_{4}\right)\right), \\
& =\left(d\left(a_{m}, S_{1}\right), d\left(a_{m}, S_{2}\right), 0,1\right),
\end{aligned}
$$


Pada graf lintasan terdapat minimal satu titik di $S_{1}$ misal $x_{1}$ yang mempunyai $d\left(x_{1}, S_{3}\right)=\infty$ dan $d\left(x_{1}, S_{4}\right)=\infty$. Sehingga dihasilkan kode warna sebagai berikut,

$$
\begin{aligned}
c_{\Pi}\left(x_{1}\right) & =\left(d\left(x_{1}, S_{1}\right), d\left(x_{1}, S_{2}\right), d\left(x_{1}, S_{3}\right), d\left(x_{1}, S_{4}\right)\right), \\
& =\left(d\left(x_{1}, x_{1}\right), d\left(x_{1}, x_{2},\right), d\left(x_{1}, a_{2},\right), d\left(x_{1}, a_{3}\right)\right), \\
& =\left(\begin{array}{ll}
0,1, \infty, \infty) .
\end{array}\right.
\end{aligned}
$$

Akibat dari kode warna diatas diperoleh $\chi_{L}^{\prime}(H)=\infty$.

Teorema 3.2. Misalkan $H=P_{n} \bigcup C_{m}$ dimana $n \geq 4$ dan $m \geq 4$ maka $\chi_{L}^{\prime}(H)=4$.

Bukti. Akan ditunjukkan bahwa $\chi_{L}^{\prime}(H)=4$ untuk $n \geq 4$ dan $m \geq 4$. Andaikan titik-titik pada graf $H$ diberikan 3-pewarnaan titik maka akan terdapat 2 titik yang mempunyai kode warna yang sama. Maka misalkan pewarnaan titik di $H$ yaitu $c: V(H) \rightarrow\{1,2,3,4\}$ sedemikian sehingga

$$
\begin{aligned}
& c\left(x_{1}\right)=c\left(a_{3}\right)=1, \\
& c\left(x_{2}\right)=c\left(a_{2}\right)=c\left(a_{5}\right)=2, \\
& c\left(x_{3}\right)=c\left(a_{1}\right)=c\left(a_{4}\right)=3, \\
& c\left(x_{4}\right)=c\left(a_{6}\right)=4 .
\end{aligned}
$$

Diperoleh kelas warna sebagai berikut $\Pi=\left\{S_{1}, S_{2}, S_{3}, S_{4}\right\}$ dengan

$$
\begin{aligned}
& S_{1}=\left\{x_{1}, a_{3}\right\}, \\
& S_{2}=\left\{x_{2}, a_{2}, a_{5}\right\} \\
& S_{3}=\left\{x_{3}, \cdots, x_{n}, a_{1}, a_{4}, a_{7}, \cdots, a_{m-1}\right\}, \\
& S_{4}=\left\{x_{4}, \cdots, x_{n}, a_{6}, \cdots, a_{m}\right\} .
\end{aligned}
$$

Kode warna setiap titik di $H$ terhadap $\Pi$ sebagai berikut,

$$
\begin{aligned}
& c_{\Pi}\left(x_{1}\right)=\left(d\left(x_{1}, S_{1}\right), d\left(x_{1}, S_{2}\right), d\left(x_{1}, S_{3}\right), d\left(x_{1}, S_{4}\right)\right), \\
& =(0,1,2,3) \text {, } \\
& c_{\Pi}\left(x_{2},\right)=\left(d\left(x_{2}, S_{1}\right), d\left(x_{2}, S_{2}\right), d\left(x_{2}, S_{3}\right), d\left(x_{2}, S_{4}\right)\right) \text {, } \\
& =(1,0,1,2) \text {, } \\
& c_{\Pi}\left(x_{3}\right)=\left(d\left(x_{3}, S_{1}\right), d\left(x_{3}, S_{2}\right), d\left(x_{3}, S_{3}\right), d\left(x_{3}, S_{4}\right)\right), \\
& =(2,1,0,1) \text {, }
\end{aligned}
$$

Untuk $r \in[4, n]$

$$
\begin{aligned}
c_{\Pi}\left(x_{4}\right) & =\left(d\left(x_{4}, S_{1}\right), d\left(x_{4}, S_{2}\right), d\left(x_{4}, S_{3}\right), d\left(x_{4}, S_{4}\right)\right), \\
& =(3,2,1,0),
\end{aligned}
$$




$$
\begin{aligned}
& c_{\Pi}\left(x_{n-1}\right)=\left(d\left(x_{n-1}, S_{1}\right), d\left(x_{n-1}, S_{2}\right), d\left(x_{n-1}, S_{3}\right), d\left(x_{n-1}, S_{4}\right)\right) \text {, } \\
& =(r-1, r-2,0,1) \text { untuk } n \text { ganjil }, \\
& c_{\Pi}\left(x_{n-1}\right)=\left(d\left(x_{n-1}, S_{1}\right), d\left(x_{n-1}, S_{2}\right), d\left(x_{n-1}, S_{3}\right), d\left(x_{n-1}, S_{4}\right)\right) \text {, } \\
& =(r-1, r-2,1,0) \text { untuk } n \text { genap }, \\
& c_{\Pi}\left(a_{1}\right)=\left(d\left(a_{1}, S_{1}\right), d\left(a_{1}, S_{2}\right), d\left(a_{1}, S_{3}\right), d\left(a_{1}, S_{4}\right)\right), \\
& =(1,1,0,3) \text {, } \\
& c_{\Pi}\left(a_{2},\right)=\left(d\left(a_{2}, S_{1}\right), d\left(a_{2}, S_{2}\right), d\left(a_{2}, S_{3}\right), d\left(a_{2}, S_{4}\right)\right) \text {, } \\
& =(2,0,1,2) \text {, } \\
& c_{\Pi}\left(a_{3}\right)=\left(d\left(a_{3}, S_{1}\right), d\left(a_{3}, S_{2}\right), d\left(a_{3}, S_{3}\right), d\left(a_{3}, S_{4}\right)\right), \\
& =\left(0,1,1, d\left(a_{3}, S_{4}\right)\right), \\
& c_{\Pi}\left(a_{4}\right)=\left(d\left(a_{4}, S_{1}\right), d\left(a_{4}, S_{2}\right), d\left(a_{4}, S_{3}\right), d\left(a_{4}, S_{4}\right)\right), \\
& =(3,1,0,1) \text {, } \\
& c_{\Pi}\left(a_{5}\right)=\left(d\left(a_{5}, S_{1}\right), d\left(a_{5}, S_{2}\right), d\left(a_{5}, S_{3}\right), d\left(a_{5}, S_{4}\right)\right) \text {, } \\
& =\left(1,0,1, d\left(a_{5}, S_{4}\right)\right), \\
& c_{\Pi}\left(a_{6}\right)=\left(d\left(a_{6}, S_{1}\right), d\left(a_{6}, S_{2}\right), d\left(a_{6}, S_{3}\right), d\left(a_{6}, S_{4}\right)\right) \text {, } \\
& =(4,2,1,0) \text {, }
\end{aligned}
$$

Untuk $s \in[7, m]$

$$
\begin{aligned}
c_{\Pi}\left(a_{7}\right) & =\left(d\left(a_{7}, S_{1}\right), d\left(a_{7}, S_{2}\right), d\left(a_{7}, S_{3}\right), d\left(a_{7}, S_{4}\right)\right), \\
& =\left(2,1, \quad 0, d\left(a_{7}, S_{4}\right)\right), \\
\vdots & \\
c_{\Pi}\left(a_{m-1}\right) & =\left(d\left(a_{m-1}, S_{1}\right), d\left(a_{m-1}, S_{2}\right), d\left(a_{m-1}, S_{3}\right), d\left(a_{m-1}, S_{4}\right)\right), \\
& =\left(d\left(a_{m-1}, S_{1}\right), d\left(a_{m-1}, S_{2}\right), 0,1\right), \\
c_{\Pi}\left(a_{m}\right) & =\left(d\left(a_{m}, S_{1}\right), d\left(a_{m}, S_{2}\right), d\left(a_{m}, S_{3}\right), d\left(a_{m}, S_{4}\right)\right), \\
& =\left(d\left(a_{m}, S_{1}\right), d\left(a_{m}, S_{2}\right), 1,0\right) .
\end{aligned}
$$

Dari kode warna diatas dapat dilihat bahwa setiap titik pada $H$ memiliki kode warna yang berbeda, akibatnya $c$ adalah pewarnaan lokasi pada graf $H$ dengan $n \geq 4$ dan $m \geq 4$. Jadi, $\chi_{L}^{\prime}(H)=4$ untuk $n \geq 4$ dan $m \geq 4$.

\section{Kesimpulan}

Pada makalah ini telah ditentukan bilangan kromatik lokasi graf tak terhubung $H$ yang memuat graf lintasan $P_{n}$ dengan $n$ titik dan graf lingkaran $C_{m}$ dengan $m$ titik, dimana dinotasikan sebagai $H \simeq P_{n} \cup C_{m}$.

\section{Ucapan Terima kasih}

Penulis mengucapkan terima kasih kepada Bapak Dr. Admi Nazra, Ibu Dr. Lyra Yulianti, dan Bapak Yudiantri Asdi, M.Sc selaku dosen penguji yang telah memberikan kritik dan saran dalam penulisan makalah ini. 


\section{Daftar Pustaka}

[1] Asmiati and E.T. Baskoro, 2012. Characterizing All Graphs Containing Cycles With Locating-Chromatic Number. AIP Conf. Proc. 321 - 357.

[2] Bondy, J.A.,U.S.R. Murty. 1976. Graph Theory with Application. Elsevier Science Publishing, New York.

[3] Chartrand, G., Erwin, D., Henning, M.A., Slater, P.J. dan Zhang, P. 2002. The Locating Chromatic Number of a Graph. Bull Inst. Combin. Appl. 36: 89-101.

[4] Chartrand, G., Erwin, D., Henning, M.A., Slater, P.J. dan Zhang, P. 2003. Graph of Order $n$ With Locating-Chromatic Number $n-1$. Discrete Math. 269: $65-79$.

[5] Welyyanti, D., Baskoro, E.T, Simanjuntak, R., Utunggadewa, S. 2014. The Locating-Chromatic Number of Disconnected Graph. Far East Journal of Mathematical Sciences. 94(2): 169 - 182. 